\title{
Effects of customized risk reduction program on cardiovascular risk in males with spinal cord injury
}

\author{
Jonathan Myers, PhD; ${ }^{*}$ Ramya Gopalan, MS, MPH; Troy Shahoumian, MPH, PhD; Jenny Kiratli, PhD \\ Spinal Cord Injury Center and Cardiology Division, Department of Veterans Affairs Palo Alto Health Care System, and \\ Stanford University, Palo Alto, CA
}

\begin{abstract}
Persons with spinal cord injury (SCI) have heightened risk for cardiovascular disease (CVD). Multidisciplinary risk reduction programs using case management models have been effective in reducing CVD risk in nondisabled persons, but little is known regarding the effects of such programs in SCI. Twenty-six persons with SCI underwent a pilot 2 yr risk intervention program including frequent telephone contact by a case manager and in-person visits by a dietitian, physical therapist, and exercise physiologist. At 6 mo intervals, measurements were made of dietary intake, glucose and lipids, physical activity patterns, and exercise capacity. Of the 26 participants, 10 remained in the program for the full $2 \mathrm{yr}$; medical issues unrelated to the program were the major reasons for dropping out. Significant improvements were observed in weight, plasma insulin, homeostatic model assessment insulin resistance, and total cholesterol/high-density lipoprotein ratio, although these changes were not consistent across visits. No differences in estimates of physical activity patterns were demonstrated, nor were differences in dietary macronutrient intake observed. Thus, modest changes in some CVD risk markers can be achieved by a multidisciplinary risk reduction program in SCI. Such programs present more challenges than in ambulatory persons, and more intensive risk intervention may be required to appreciably reduce CVD risk in SCI.
\end{abstract}

Key words: case management, diabetes, diet, exercise testing, heart disease, insulin resistance, obesity, paraplegia, physical activity, spinal cord injury.

\section{INTRODUCTION}

Historically, respiratory and renal conditions have been the most common causes of mortality in the spinal cord injury (SCI) population [1-3]. However, as the life span in persons with SCI has lengthened, a greater frequency of aging-related conditions has evolved [1,4]. In particular, data published in recent years suggest that cardiovascular disease (CVD) has become a highly prevalent cause of mortality in SCI. Morbidity from cardiovascular causes, particularly coronary artery disease (CAD), is high relative to the general population, and CAD tends to occur earlier in individuals with SCI than among ambulatory persons [3-6]. A major contributor to the heightened

\footnotetext{
Abbreviations: $\mathrm{BMI}=$ body mass index, $\mathrm{CAD}=$ coronary artery disease, $\mathrm{CVD}=$ cardiovascular disease, $\mathrm{FEV}_{1}=$ forced expiratory volume in $1 \mathrm{~s}$, FRS = Framingham Risk Score, FVC = forced vital capacity, HDL = high-density lipoprotein, HOMAIR = homeostasis model of assessment-insulin resistance, MET $=$ metabolic equivalent, $\mathrm{NIH}=$ National Institutes of Health, PASIPD = Physical Activity Scale for Individuals with Physical Disabilities, $\mathrm{SCI}=$ spinal cord injury, $\mathrm{SD}=$ standard deviation, VA = Department of Veterans Affairs, VAPAHCS = VA Palo Alto Health Care System, VAPAQ $_{\text {SCI }}=$ VA Physical Activity Questionnaire modified for SCI.

*Address all correspondence to Jonathan Myers, PhD; VA Palo Alto Health Care System, Cardiology Division (111C), 3801 Miranda Avenue, Palo Alto, CA 94304; 650-493-5000, ext 64661; fax: 650-852-3473. Email: Drj993@aol.com http://dx.doi.org/10.1682/JRRD.2011.11.0215
} 
risk of CVD after SCI is the fact that metabolic risks, including hyperlipidemia, obesity, and diabetes, have been shown to be particularly common among these individuals [3,6-11]. Recognition and intervention for CVD risk is an emerging clinical challenge in this population.

An additional contributing factor to the high cardiovascular morbidity and mortality in SCI is the sedentary lifestyle and reduced physical function associated with loss of motor function [3,12-14]. Participation in physical activity for persons with SCI is limited not only by the obvious physical barriers but also by limited availability of facilities and transportation, as well as psychosocial barriers. Additional impediments to physical activity may include social isolation, low motivation, low self-esteem or even depression, and poor body image [15-16]. While it is well known that greater physical activity confers significant benefits on health and longevity in ambulatory individuals, whether it confers the same level of benefit in persons with SCI has not been adequately explored. Roughly two-thirds of Americans do not meet the minimal recommendations for physical activity, and it has been suggested that this number is in the range of 80 to 90 percent in persons with SCI $[9,17]$. Therefore, because of these physical and psychosocial barriers, few individuals with SCI achieve the benefits of physical activity available to ambulatory persons. These impediments to physical activity no doubt further contribute to heightened CVD risk in SCI [3,9-16].

Nutrition and energy balance among persons with SCI have also been widely studied in recent years. Resting metabolic rates are comparatively low in SCI, and total energy expenditure has been reported to be approximately 20 percent lower in individuals with paraplegia than in ambulatory persons [18-19]. Dietary patterns have been shown to be generally poor in persons with SCI; much like the general U.S. population, dietary intakes in persons with SCI tend to be high in fat, low in complex carbohydrates, low in fiber, and lacking in particular micronutrients [20-21]. These issues have been suggested to underlie higher rates of obesity, abnormal lipid profiles, and insulin resistance in persons with SCI [19]. While efforts have been made to study the effects of dietary modification on atherogenic risk in SCI [22], there is a paucity of data available regarding dietary reference standards for persons with SCI. A 2009 American Dietetic Association evidence-based practice guideline on nutritional needs for SCI emphasized the need for nutri- tional intervention in order to improve the nutritional status and weight management of persons with SCI [23].

A need exists to explore models designed to reduce CVD risk in persons with SCI. Case management methods, which emphasize a multidisciplinary team approach and numerous patient contacts, have been shown to be effective in modifying risk and reducing mortality among ambulatory persons with CVD [24]. In fact, such programs have been incorporated into treatment guidelines for patients with chronic heart failure and post-myocardial infarction patients referred for cardiac rehabilitation [2526]. However, little is known regarding such programs among individuals following SCI. Moderate success has been achieved using targeted programs for weight loss [27], lipid modification [28], and physical activity participation [29], but few data are available on comprehensive, multidisciplinary approaches to reduce cardiac risk after SCI. Using methods similar to those that have been successful among ambulatory post-myocardial infarction subjects [24], we employed a case-managed approach in an effort to reduce CVD risk in a group of patients followed at our SCI Center. The program, termed Customized Health Assessment and Risk Management, was a pilot study that sought to determine the influence of a multidisciplinary risk management program on CVD risk in persons with SCI over a 2 yr period.

\section{METHODS}

\section{Participants and Recruitment}

We recruited 26 male patients with SCI (mean \pm standard deviation [SD] age $57 \pm 6 \mathrm{yr}$ ) at high risk for CVD from the Department of Veterans Affairs (VA) Palo Alto Health Care System (VAPAHCS) SCI Center. Of the 26 participants, 10 had a cervical, 13 a thoracic, and 3 a lumbar level of injury. All SCI subjects were nonambulatory. American Spinal Injury Association Classification and other clinical, risk factor, and demographic characteristics of the participants are presented in Table 1. CVD risk was determined by calculating the Framingham Risk Score (FRS) [30] initially from information in the electronic medical record and confirmed during screening. Only persons with an FRS associated with an age-adjusted 20 percent or greater $10 \mathrm{yr}$ absolute risk of CVD, but no overt CVD, were considered eligible for inclusion. Of the approximately 800 veterans served at our SCI Center annually, we estimate that about 50 percent would meet 
Table 1.

Clinical and demographic characteristics of participants at entry $(N=26)$.

\begin{tabular}{lc}
\hline \multicolumn{1}{c}{ Characteristic } & Value \\
\hline Age, Current (yr), mean \pm SD (range) & $56.92 \pm 5.74(45-69)$ \\
Height (in.), mean \pm SD (range) & $70.75 \pm 2.52(66-76)$ \\
Weight (lb), mean \pm SD (range) & $213.29 \pm 38.6(155-288)$ \\
BMI (kg/m ${ }^{2}$ ), mean \pm SD (range) & $29.87 \pm 5.16(22.6-40.2)$ \\
Time Since Injury (yr), mean \pm SD (range) & $23.8 \pm 12.3(2-50)$ \\
Risk Factors, No. (\%) & \\
Smoking (past or current) & $4(15.4)$ \\
Hypertension & $2(7.7)$ \\
Hyperlipidemia & $19(73.1)$ \\
Type 2 Diabetes & $6(23.1)$ \\
Overweight (BMI 25-30 kg/m²) & $10(38.5)$ \\
Obesity (BMI > 30 kg/m $\left.{ }^{2}\right)$ & $11(42.3)$ \\
Level of Injury, No. & 10 \\
Cervical & 13 \\
Thoracic & 3 \\
Lumbar & \\
ASIA Classification, No. (\%) & $9(34.6)$ \\
Tetraplegia, ASIA A \& B & 0 \\
Tetraplegia, ASIA C & $8(30.8)$ \\
Paraplegia, ASIA A \& B & $4(15.4)$ \\
Paraplegia, ASIA C & $5(19.2)$ \\
All ASIA D & \\
\hline ASIA = American Spinal Injury Association, BMI = body mass index, SD \\
standard deviation. \\
\hline \hline
\end{tabular}

this criterion. At baseline, a complete cardiovascular examination was performed. Historical and current information on tobacco use, blood lipids, body mass index (BMI), hypertension, physical activity patterns, blood glucose, and other risk information was obtained.

\section{Study Design}

This study was a pilot evaluation, with each subject as his own control. After recruitment and initial testing, participants underwent a baseline visit that included blood analyses; dietary, lifestyle, and physical activity questionnaires; a maximal exercise test; an evaluation by a physical therapist; and recommendations for individualized exercise and nutrition plans. Using a case management model [31], participants were then contacted by phone weekly during the first 6 weeks, then again at $8 \mathrm{wk}$ and at 3, 4, 5, and 6 mo. This was followed by complete evaluations in the SCI Center at 12, 18, and 24 mo, during which all the baseline measurements were repeated.

\section{Measures of Cardiac Risk}

A full blood lipid profile, including total cholesterol, high-density lipoprotein (HDL), low-density lipoprotein, and triglycerides, along with homocysteine, high sensitivity C-reactive protein, fasting glucose, insulin and the homeostasis model of assessment-insulin resistance (HOMA-IR) were determined at each study visit. All blood samples were drawn and processed at the VAPAHCS laboratory using standardized techniques. Body dimensions were expressed as BMI (weight in kilograms divided by height in meters squared) determined from direct weighing on a scale (wheelchair with participant minus wheelchair alone) and self-reported height. Resting blood pressure was averaged from two separate measurements after the participant rested in the supine position for a minimum of $10 \mathrm{~min}$. Five participants were included who had a current diagnosis of type 2 diabetes; there were no type 1 diabetics, and all had fasting glucose levels controlled pharmacologically.

\section{Exercise Testing}

Exercise testing was performed using individualized tests in our SCI exercise research laboratory. Standard pulmonary function tests were performed prior to the exercise test, with measures of forced vital capacity (FVC), forced expiratory volume in $1 \mathrm{~s}\left(\mathrm{FEV}_{1}\right)$, and peak expiratory flow obtained and expressed as a percentage of normal using American Thoracic Society Standards [32]. Maximal exercise testing was performed using an electronically braked arm ergometer in the upright seated position with the wheelchair secured. Study participants were requested to maintain the arm crank cadence at $60 \mathrm{rpm}$ throughout the test. Changes in resistance of the arm ergometer were individualized such that the test duration ranged from 8 to $12 \mathrm{~min}$, and the same ramp rate was used for a given person for each test throughout the follow-up period. A standard 12-lead electrocardiogram and ventilatory gas exchange data were obtained throughout the exercise test and recovery period. Perceived exertion was recorded each minute using the Borg 6-20 scale [33]. All participants were encouraged to give a maximal effort; tests were terminated when volitional fatigue occurred, when the participant was no longer able to maintain a cadence of $60 \mathrm{rpm}$, or both.

\section{Activity Monitoring}

Activity status was quantified using the Physical Activity Scale for Individuals with Physical Disabilities (PASIPD) [34], the VA Physical Activity Questionnaire

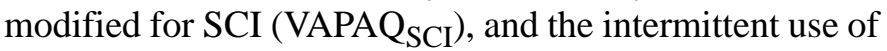
an accelerometer. The PASIPD is a 13-item scale designed to provide information on leisure, household, 
and occupational activities. A PASIPD composite physical activity score was derived and expressed as metabolic equivalent (MET)-hours/day. The VAPAQ $\mathrm{SCI}_{\mathrm{SCI}}$ entails an interview in which subjects describe detailed daily recreational and occupational activities. The VAPAQ has been extensively used in epidemiologic studies to quantify activity patterns among ambulatory persons expressed in kilocalories per day [35]. In our modified version (VAPAQ ${ }_{\mathrm{SCI}}$ ), energy costs of activities were based on those developed by Collins et al. [36] for persons with SCI. To obtain objective measures of activity, an accelerometer (ActiGraph model GT1M; Pensacola, Florida) was used for $3 \mathrm{~d}$ periods at the time of each study visit. The accelerometer is a small $(3.8 \times 3.7 \times 1.5 \mathrm{~cm})$ lightweight (42.6 g) uniaxial device attached to the dominant wrist that measures acceleration in the vertical plane. The device contains a piezoelectric sensor that generates a voltage signal in proportion to acceleration caused by tension-induced deformation of the sensor. It was initialized to collect data in $1 \mathrm{~s}$ epochs, and the results were downloaded directly to a computer using a USB cable. The algorithm described by Crouter et al. [37] was used to convert accelerometry data (counts) into METs, and kilocalories per minute were determined using $\mathrm{kcals} / \mathrm{min}=$ $($ METs $\times 3.5 \times$ body weight in $\mathrm{kg}) / 200$.

\section{Dietary Intake}

Dietary intake was quantified using the Block food frequency questionnaire [38]. Participants were asked to record dietary intake in accordance with a random schedule during a $3 \mathrm{~d}$ period, including one weekend day. Nutrient analysis of the diet was recorded throughout, including total calorie intake, intake of macronutrients (fat, protein, carbohydrates), percent calories from fat, percent calories from saturated fat, polyunsaturated to saturated fat ratio, fiber, and cholesterol intake.

\section{Risk Management Intervention and Monitoring}

The risk management program was physiciansupervised but managed by nonphysician health professionals. During an initial visit, measurements were obtained as described previously, and patients received both verbal and written educational materials specific to their individual risk factors. A schedule was established for subsequent telephone contacts and clinic visits. Nutritional counseling, smoking intervention, and lipidlowering therapy were provided individually to meet therapeutic goals. Participants were triaged to the VAPAHCS
Smoking Cessation, Diabetes, and Lipid Management Clinics as appropriate. Interventions were evidence-based, using current consensus statements as guidelines for both treatment and therapeutic goals. Appropriate treatments were tailored to meet consensus statement guidelines, including the National Institutes of Health (NIH) National Cholesterol Educational Program, the Centers for Disease Control/American College of Sports Medicine recommendations for physical activity, the American Heart Association Dietary Guidelines, and the NIH Consensus Statement on Detection and Treatment of High Blood Pressure [30]. Maximal exercise tests at each visit were coupled with a counseling session with a physical therapist to review the individual's activity capabilities and provide activity recommendations. During each of the visits, pharmacologic therapy was revised as needed and additional assistance with diet, exercise, or smoking cessation was provided on an individualized basis in order to optimize both treatment of risk factors and compliance with dietary and lifestyle recommendations.

\section{Analysis}

Data are presented as mean \pm SD. All measurements were compared to baseline at each measurement interval, initially using $t$-tests for paired observations. Because the number of comparisons changed at each measurement point and the data were not normally distributed, binomial sign tests were used to explore whether differences existed in medians between the distributions of each variable at each evaluation. This permitted an evaluation of the ratio of the number of participants who improved versus those who worsened at each evaluation. The latter comparisons are reported in the tables. The strength of the changes in the various risk markers was assessed by calculation of effect size.

\section{RESULTS}

At baseline, the sample included 73 percent with hyperlipidemia, 15 percent past or current smokers, 23 percent diabetics, and 81 percent overweight or obese (Table 1). From the original sample of 26 persons enrolled, 22, 18, 15, and 10 completed 6 mo, 12 mo, $18 \mathrm{mo}$, and 24 mo, respectively. Medical issues were the main reason for dropping out, followed by personal reasons, inability to comply, travel issues, and inability to commit the time necessary to continue. Medical reasons 
for dropping out included pressure sores (2 cases), back pain (2 cases), hand surgery (1 case), and uncontrolled dyslipidemia ( 1 case). Two participants died between the 12 and 18 mo evaluations, both from multiple organ system failure unrelated to the study.

Intervention effects on key risk markers at each measurement point are presented in Table 2. Weight was reduced slightly at each follow-up point, but was significantly lower only for the comparison between baseline and 6 mo $(\approx 4 \mathrm{lb}, p=0.004)$. Fasting glucose did not change significantly, but mean values for both insulin and HOMA-IR were significantly lower at each comparison than at baseline. Reductions in insulin and HOMA-IR were confirmed by sign tests at the 6 and 12 mo evaluations, in which 90 and 94 percent of participants exhibited reductions in insulin level, and 85 and 88 percent of subjects exhibited reductions in HOMA-IR at 6 and 12 mo, respectively ( $p<0.01$ for all). Among lipid profiles, total cholesterol/HDL ratio was lower at the 6 mo evaluation ( $p=0.05)$ and triglycerides tended to be lower at each evaluation $(\approx 10 \%-20 \%)$. Total cholesterol was 3 to 7 percent lower at each evaluation, but none of these comparisons reached statistical significance. Calculation of effect sizes indicated a strong effect only for insulin and HOMA-IR (effect sizes $\approx 0.80-0.90$ at each evaluation point). Effect sizes for weight and lipid measures were generally $<0.20$, suggesting that the size of the effect was small.

Exercise test responses, physical activity parameters, and macronutrient intakes at each evaluation point are presented in Table 3. FEV 1 was significantly higher at 18 mo, and all but one subject increased FVC at this point ( $p=0.07$ ); however, these indices did not differ at other evaluations. No other exercise test variables dif- fered between matching evaluation points. No differences were observed in objective or subjective estimates of physical activity patterns at any of the measurement intervals. No significant differences were observed in total calories, percentage of fat, carbohydrates, protein, or macronutrient intake at each matched comparison. However, the average total calories consumed at each of the time points was considerably lower than the average caloric intake observed in the U.S. general population (approximately 2,400 calories) as reported in the National Health and Nutrition Examination Survey III data [39]. In addition, caloric and macronutrient intakes were generally below the recommended Dietary Reference Intake standards for a comparable age/sex group.

\section{DISCUSSION}

The Healthy People 2020 report [40] and a 2009 National Council on Disability report entitled "The current state of health care for persons with disabilities" [17] emphasized the role of cardiovascular risk assessment and management in adults with chronic SCI and included objectives directed toward reducing barriers to participation in physical activity in persons with disabilities. Clearly, there has been a recent appreciation for the importance of modifying CVD risk after SCI [3,10-12,14,17,41]. While previous efforts at comprehensive risk reduction have been successful in ambulatory persons using metrics that include lipid profiles, body dimensions, and even angiographic CAD [27-28,41], such programs in persons with SCI are more challenging. Barriers to effective risk reduction in SCI include lack of availability of exercise facilities and limited

Table 2.

Intervention effects at each measurement interval on key risk markers (mean \pm standard deviation).

\begin{tabular}{|c|c|c|c|c|c|c|c|c|c|c|c|c|}
\hline \multirow{2}{*}{ Variable } & \multicolumn{3}{|c|}{6 Months $(n=22)$} & \multicolumn{3}{|c|}{12 Months $(n=18)$} & \multicolumn{3}{|c|}{18 Months $(n=15)$} & \multicolumn{3}{|c|}{24 Months $(n=10)$} \\
\hline & Baseline & Follow-Up l & $p$-Value & Baseline & Follow-Up & $p$-Value & Baseline & Follow-Up & $p$-Value & Baseline & Follow-Up l & $p$-Value \\
\hline Weight & $210.5 \pm 38.0$ & $206.7 \pm 34.0$ & 0.004 & $210.9 \pm 35.0$ & $207.1 \pm 38.0$ & 0.48 & $204.5 \pm 36.0$ & $200.8 \pm 36.0$ & 0.58 & $220.5 \pm 40.0$ & $219.5 \pm 5.01$ & $>0.99$ \\
\hline Cholesterol & $162.4 \pm 37.0$ & $157.1 \pm 32.0$ & $>0.99$ & $163.4 \pm 39.0$ & $156.4 \pm 35.0$ & 0.81 & $170.1 \pm 39.0$ & $162.7 \pm 39.0$ & 0.18 & $175.8 \pm 42.0$ & $163.8 \pm 41.0$ & 0.34 \\
\hline LDL & $98.4 \pm 32.0$ & $94.0 \pm 31.0$ & $>0.99$ & $97.7 \pm 33.0$ & $92.1 \pm 37.0$ & $>0.99$ & $102.7 \pm 34.0$ & $98.0 \pm 33.0$ & $>0.99$ & $109.7 \pm 36.0$ & $98.0 \pm 35.0$ & 0.11 \\
\hline HDL & $42.0 \pm 11.0$ & $42.8 \pm 14.0$ & 0.52 & $42.1 \pm 12.0$ & $45.2 \pm 16.0$ & 0.48 & $42.1 \pm 12.0$ & $44.6 \pm 14.0$ & 0.18 & $38.3 \pm 11.0$ & $41.4 \pm 14.0$ & 0.34 \\
\hline $\begin{array}{l}\text { Cholesterol/ } \\
\text { HDL Ratio }\end{array}$ & $4.1 \pm 1.3$ & $4.0 \pm 1.4$ & 0.13 & $4.2 \pm 1.4$ & $3.9 \pm 1.5$ & 0.05 & $4.3 \pm 1.4$ & $3.9 \pm 1.4$ & 0.09 & $4.8 \pm 1.5$ & $4.2 \pm 1.3$ & 0.11 \\
\hline Triglycerides & $110.2 \pm 54.0$ & $101.2 \pm 58.0$ & 0.13 & $118.7 \pm 55.0$ & $95.4 \pm 49.0$ & 0.24 & $127.1 \pm 57.0$ & $100.9 \pm 50.0$ & 0.12 & $139.1 \pm 58.0$ & $122.1 \pm 63.0$ & 0.11 \\
\hline Glucose & $101.8 \pm 14.0$ & $100.2 \pm 10.0$ & $>0.99$ & $102.4 \pm 15.0$ & $105.6 \pm 21.0$ & 0.33 & $104.8 \pm 13.0$ & $100.4 \pm 12.0$ & 0.11 & $102.9 \pm 13.0$ & $96.0 \pm 8.0$ & 0.11 \\
\hline Insulin & $16.7 \pm 13.4$ & $8.4 \pm 5.9$ & 0.001 & $17.6 \pm 14.0$ & $9.0 \pm 5.1$ & 0.001 & $20.9 \pm 16.0$ & $9.9 \pm 5.7$ & 0.15 & $27.6 \pm 15.0$ & $14.7 \pm 8.0$ & 0.29 \\
\hline HOMA-IR & $4.4 \pm 3.7$ & $2.21 \pm 1.8$ & 0.003 & $4.7 \pm 3.9$ & $2.4 \pm 1.6$ & 0.002 & $5.6 \pm 4.3$ & $2.6 \pm 1.7$ & 0.39 & $7.4 \pm 4.2$ & $3.7 \pm 2.4$ & 0.29 \\
\hline
\end{tabular}


JRRD, Volume 49, Number 9, 2012

Table 3.

Exercise test responses, physical activity, and macronutrient intake at each measurement interval.

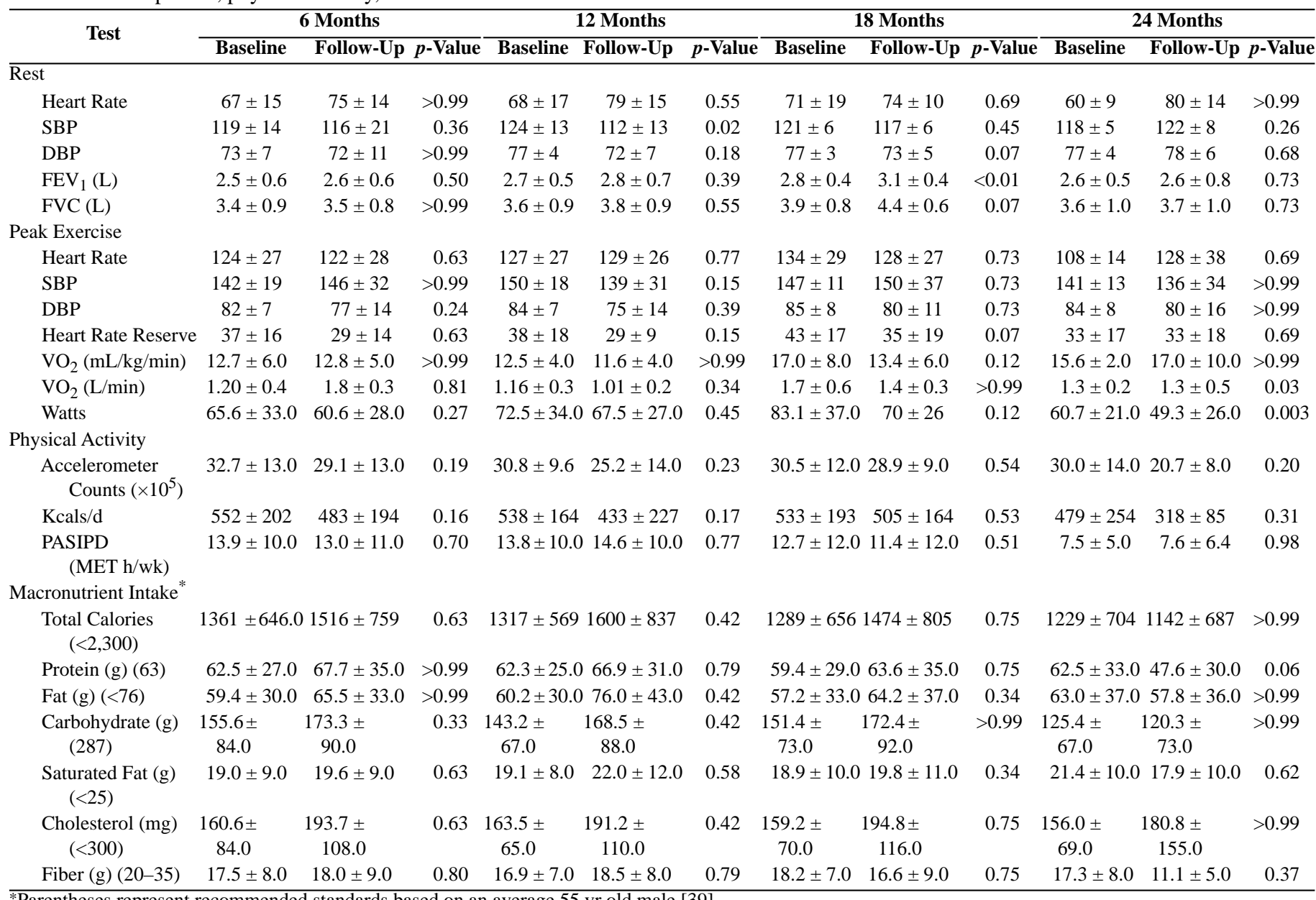

*Parentheses represent recommended standards based on an average 55 yr old male [39].

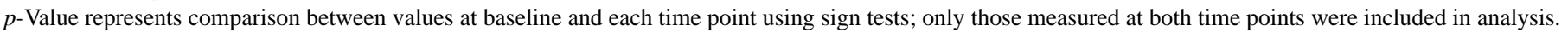

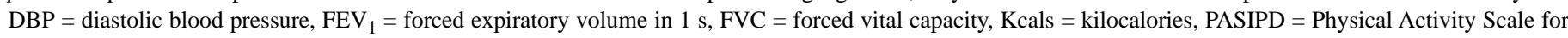
Individuals with Physical Disabilities, $\mathrm{SBP}=$ systolic blood pressure, $\mathrm{VO}_{2}=$ oxygen uptake.

accessibility and transportation to medical care. While some, but not all, previous interventions targeting exercise capacity [42], weight management [27], or lipid profiles [28] have demonstrated CVD risk may be improved in SCI, these studies have generally targeted one risk marker and were short-term, and little is known regarding multidisciplinary risk reduction over longer periods such as 1 to $2 \mathrm{yr}$. The current study was a pilot effort to fill these gaps by assessing the efficacy of a $2 \mathrm{yr}$, evidence-based program of multidisciplinary risk reduction in a SCI cohort.

We observed modest changes in several markers of CVD risk; in particular, weight reduction and improvements in insulin level, HOMA-IR, and total cholesterol/ HDL ratio (Table 2). While many of the other risk markers showed tendencies to improve, these changes were small and not consistent enough across time or individuals to demonstrate statistical or clinically significant change. In addition, these observations cannot be directly attributed to dietary changes or higher physical activity per se, since neither of these improved appreciably, at least inasmuch as questionnaire approaches can detect such changes. The possibility exists that lifestyle modifications occurred that we did not measure or that the tools we employed were not sensitive enough to detect changes. Overall, our findings suggest that standard casemanagement approaches to risk reduction that have been successful in ambulatory persons achieve only comparatively modest success in those with SCI, and alternative, perhaps more intensive models are needed to address the problem of CVD risk after SCI. It may also be important 
to consider models more conducive to addressing barriers to participation unique to individuals with SCI.

There were several encouraging observations regarding CVD risk; the consistent reduction in insulin levels at each evaluation is noteworthy. High circulating insulin levels are usually a consequence of insulin resistance and have been associated with adverse cardiac events independent of other CVD risk markers [43]. Hyperinsulinemia is also a major factor underlying abnormal lipid metabolism in SCI [10]. In persons with SCI, plasma insulin levels are higher following glucose tolerance testing compared with ambulatory persons and are elevated with higher levels of injury [44]. We observed a roughly 50 percent reduction in plasma insulin at each visit compared with baseline, which would appear to represent a clinically significant change (Table 2). The effects of this degree of reduction on long-term CVD risk in persons with SCI are unknown but encouraging. Since the clinical implications of persistently elevated plasma insulin include higher risk for CVD, higher prevalence of virtually all the major metabolic risk markers, and higher cardiovascular morbidity [7,10,43-45], efforts to reverse these are warranted. We did not observe changes in activity patterns or exercise capacity, although it should be noted that our study was not directed toward exercise training per se. Rather, we attempted to optimize functional capabilities, minimize pain, and identify available modalities for each participant.

Another notable response was change in body weight; there was a consistent $\approx 4 \mathrm{lb}$ reduction from baseline to each visit up to 18 mo. Although the change was significant only at $6 \mathrm{mo}$, the reduction in study numbers likely accounts for the lack of significant change at subsequent visits. Obesity has long been a concern in persons with SCI, not only because of its high prevalence $[11,19,46]$, but also because, similar to in ambulatory individuals, obesity has been associated with glucose intolerance, hyperlipidemia, hypertension, and other metabolic abnormalities in those with SCI $[7,47]$. In an intensive intervention program specifically targeting obesity in 16 persons with SCI, Chen et al. reported 7.7 and $6.4 \mathrm{lb}$ reductions in body weight at 12 and 24 weeks, respectively [27]. The modest reduction in weight observed in the current study is noteworthy given that our sample was borderline obese at the time of recruitment (mean BMI $29.9 \mathrm{~m} / \mathrm{kg}^{2}$ ) and by the consistent observation that BMI underestimates body fat in SCI [47]. While longitudinal studies assessing weight gain following SCI are lacking, it is well established that there is a general and progressive weight gain in the years after injury [48]. Thus, although the observed changes in weight were small, counteracting the inevitable weight gain (that is, the absence of a gain in weight) in persons with SCI through dietary counseling may have long-term benefits for metabolic risk.

The dropout rate in our study is notable; only $\approx 40$ percent of the participants remained in the study at the end of 2 yr. While this was not unexpected in an elderly population with SCI, it underscores another of the challenges associated with risk intervention in these individuals. Not surprisingly, medical issues were the most common reason for dropping out. These medical issues included two deaths, pressure sores, orthopedic problems, and uncontrolled dyslipidemia. All of the other reasons for dropping out cited by participants were largely practical (time commitment, travel issues, scheduling conflicts, and inability or unwillingness to comply) and are no doubt accentuated by the presence of SCI. The adherence rate we observed is typical of other intervention studies in individuals with SCI, in which the majority of dropouts were due to illness or transportation difficulties [49]. Future efforts in this area need to consider the low adherence rate and thus modifications to study design which accommodate the realities of this condition [50].

Our study was limited by the relatively low adherence rate, a common problem in trials of persons with SCI [50]. We did not have a control group with which to compare and therefore do not have information on how these risk markers respond to usual care. The possibility of type I error is a concern given the many comparisons performed. We did not measure indices of body dimensions other than BMI; it is recognized that BMI does not adequately capture the health effects of obesity and that BMI underestimates body fat in SCI [47]. In addition, accelerometry devices have been validated in ambulatory subjects using lower-limb exercise, and little is known regarding their application to upper-limb activity in SCI. Finally, our study included only males and thus may not apply to females.

\section{CONCLUSIONS}

Modest but significant changes in CVD risk can be achieved by a multidisciplinary risk reduction program in 
persons with SCI. Such programs present more challenges than those in ambulatory subjects, and achieving the goals recommended in recent consensus reports focusing on SCI [17] may require novel or creative approaches and/or more intensive risk intervention in order to effectively reduce CVD risk in this population.

\section{ACKNOWLEDGMENTS}

\author{
Author Contributions: \\ Study concept and design: J. Myers, J. Kiratli. \\ Acquisition of data: J. Myers, R. Gopalan, J. Kiratli. \\ Analysis and interpretation of data: J. Myers, R. Gopalan, \\ T. Shahoumian, J. Kiratli. \\ Drafting of manuscript: J. Myers, R. Gopalan, T. Shahoumian, \\ J. Kiratli. \\ Critical revision of manuscript for important intellectual content: \\ J. Myers, R. Gopalan, T. Shahoumian, J. Kiratli. \\ Statistical analysis: J. Myers, T. Shahoumian. \\ Obtained funding: J. Myers, J. Kiratli. \\ Administrative and technical support: J. Myers, J. Kiratli. \\ Study supervision: J. Myers, J. Kiratli. \\ Financial Disclosures: The authors have declared that no competing \\ interests exist. \\ Funding/Support: This material was based on work supported by the \\ VA Rehabilitation Research and Development Service (Merit Review \\ grants B3122R and B4421-I). \\ Institutional Review: Recruitment procedures and all study-related \\ activities were reviewed and approved in advance by the Institutional \\ Review Board at Stanford University. \\ Participant Follow-Up: All subjects have been informed about study \\ publication.
}

\section{REFERENCES}

1. Frankel HL, Coll JR, Charlifue SW, Whiteneck GG, Gardner BP, Jamous MA, Krishnan KR, Nuseibeh I, Savic G, Sett P. Long-term survival in spinal cord injury: a fifty year investigation. Spinal Cord. 1998;36(4):266-74.

[PMID:9589527]

http://dx.doi.org/10.1038/sj.sc.3100638

2. DeVivo MJ, Krause JS, Lammertse DP. Recent trends in mortality and causes of death among persons with spinal cord injury. Arch Phys Med Rehabil. 1999;80(11):1411-19. [PMID:10569435]

http://dx.doi.org/10.1016/S0003-9993(99)90252-6

3. Myers J, Lee M, Kiratli J. Cardiovascular disease in spinal cord injury: an overview of prevalence, risk, evaluation, and management. Am J Phys Med Rehabil. 2007; 86(2):142-52. [PMID:17251696]

http://dx.doi.org/10.1097/PHM.0b013e31802f0247
4. Nakajima A, Honda S, Yoshimura S, Ono Y, Kawamura J, Moriai N. The disease pattern and causes of death of spinal cord injured patients in Japan. Paraplegia. 1989;27(3):163-71. [PMID:2762003] http://dx.doi.org/10.1038/sc.1989.25

5. Garshick E, Kelley A, Cohen SA, Garrison A, Tun CG, Gagnon D, Brown R. A prospective assessment of mortality in chronic spinal cord injury. Spinal Cord. 2005; 43(7):408-16. [PMID:15711609] http://dx.doi.org/10.1038/sj.sc.3101729

6. Yeo JD, Walsh J, Rutkowski S, Soden R, Craven M, Middleton J. Mortality following spinal cord injury. Spinal Cord. 1998;36(5):329-36. [PMID:9601112] http://dx.doi.org/10.1038/sj.sc.3100628

7. Lee MY, Myers J, Hayes A, Madan S, Froelicher VF, Perkash I, Kiratli BJ. C-reactive protein, metabolic syndrome, and insulin resistance in individuals with spinal cord injury. J Spinal Cord Med. 2005;28(1):20-25. [PMID:15832900]

8. Demirel S, Demirel G, Tükek T, Erk O, Yilmaz H. Risk factors for coronary heart disease in patients with spinal cord injury in Turkey. Spinal Cord. 2001;39(3):134-38.

[PMID:11326322]

http://dx.doi.org/10.1038/sj.sc.3101135

9. Lavis TD, Scelza WM, Bockenek WL. Cardiovascular health and fitness in persons with spinal cord injury. Phys Med Rehabil Clin N Am. 2007;18(2):317-31, vii. [PMID:17543775] http://dx.doi.org/10.1016/j.pmr.2007.03.003

10. Bauman WA, Spungen AM. Coronary heart disease in individuals with spinal cord injury: assessment of risk factors. Spinal Cord. 2008;46(7):466-76. [PMID:18180789] http://dx.doi.org/10.1038/sj.sc.3102161

11. Wahman K, Nash MS, Lewis JE, Seiger A, Levi R. Cardiovascular disease risk and the need for prevention after paraplegia determined by conventional multifactorial risk models: the Stockholm spinal cord injury study. J Rehabil Med. 2011;43(3):237-42. [PMID:21305240] http://dx.doi.org/10.2340/16501977-0658

12. Phillips WT, Kiratli BJ, Sarkarati M, Weraarchakul G, Myers J, Franklin BA, Parkash I, Froelicher V. Effect of spinal cord injury on the heart and cardiovascular fitness. Curr Probl Cardiol. 1998;23(11):641-716. [PMID:9830574] http://dx.doi.org/10.1016/S0146-2806(98)80003-0

13. Jacobs PL, Nash MS. Exercise recommendations for individuals with spinal cord injury. Sports Med. 2004;34(11): 727-51. [PMID:15456347] http://dx.doi.org/10.2165/00007256-200434110-00003

14. Myers J. Cardiovascular disease after SCI: Prevalence, instigators, and risk clusters. Top Spinal Cord Inj Rehabil. 2009; (3)14:1-14. http://dx.doi.org/10.1310/sci1403-1

15. Levins SM, Redenbach DM, Dyck I. Individual and societal influences on participation in physical activity following 
spinal cord injury: a qualitative study. Phys Ther. 2004; 84(6):496-509. [PMID:15161416]

16. Rimmer JH, Riley B, Wang E, Rauworth A, Jurkowski J. Physical activity participation among persons with disabilities: barriers and facilitators. Am J Prev Med. 2004;26(5): 419-25. [PMID:15165658]

\section{http://dx.doi.org/10.1016/j.amepre.2004.02.002}

17. National Council on Disability. The current state of health care for people with disabilities. Washington (DC): National Council on Disability; 2009.

18. Buchholz AC, Pencharz PB. Energy expenditure in chronic spinal cord injury. Curr Opin Clin Nutr Metab Care. 2004; 7(6):635-39. [PMID:15534431]

http://dx.doi.org/10.1097/00075197-200411000-00008

19. Feasel S, Groah SL. The impact on diet on cardiovascular disease risk in individuals with spinal cord injury. Top Spinal Cord Inj Rehabil. 2009;14:58-68.

http://dx.doi.org/10.1310/sci1403-58

20. Levine AM, Nash MS, Green BA, Shea JD, Aronica MJ. An examination of dietary intakes and nutritional status of chronic healthy spinal cord injured individuals. Paraplegia. 1992;30(12):880-89. [PMID:1287542]

http://dx.doi.org/10.1038/sc.1992.165

21. Groah SL, Nash MS, Ljungberg IH, Libin A, Hamm LF, Ward E, Burns PA, Enfield G. Nutrient intake and body habitus after spinal cord injury: an analysis by sex and level of injury. J Spinal Cord Med. 2009;32(1):25-33.

[PMID:19264046]

22. Wilt TJ, Carlson KF, Goldish GD, MacDonald R, Niewoehner C, Rutks I, Shamliyan T, Tacklind J, Taylor BC, Kane RL. Carbohydrate and lipid disorders and relevant considerations in persons with spinal cord injury. Evid Rep Technol Assess (Full Rep). 2008;163(163):1-95. [PMID:18457480]

23. Academy of Nutrition and Dietetics. Spinal cord injury evidence-based nutrition practice guideline [Internet]. Chicago (IL): Academy of Nutrition and Dietetics; 2009. Available from: http://andevidencelibrary.com/topic.cfm?cat $=3487$

24. Hill MN, Miller NH. Compliance enhancement. A call for multidisciplinary team approaches. Circulation. 1996; 93(1):4-6. [PMID:8616938] http://dx.doi.org/10.1161/01.CIR.93.1.4

25. Peterson ED, Albert NM, Amin A, Patterson JH, Fonarow GC. Implementing critical pathways and a multidisciplinary team approach to cardiovascular disease management. Am J Cardiol. 2008;102(5A):47G-56G.

[PMID:18722192]

http://dx.doi.org/10.1016/j.amjcard.2008.06.011

26. Balady GJ, Williams MA, Ades PA, Bittner V, Comoss P, Foody JA, Franklin B, Sanderson B, Southard D; American Heart Association Exercise, Cardiac Rehabilitation, and Prevention Committee; Council on Clinical Cardiology; Councils on Cardiovascular Nursing, Epidemiology and
Prevention, and Nutrition, Physical Activity, and Metabolism; American Association of Cardiovascular and Pulmonary Rehabilitation. Core components of cardiac rehabilitation/secondary prevention programs: 2007 update: a scientific statement from the American Heart Association Exercise, Cardiac Rehabilitation, and Prevention Committee, the Council on Clinical Cardiology; the Councils on Cardiovascular Nursing, Epidemiology and prevention, and Nutrition, Physical Activity, and Metabolism; and the American Association of Cardiovascular and Pulmonary Rehabilitation. J Cardiopulm Rehabil Prev. 2007;27(3):121-29. [PMID:17558191]

27. Chen Y, Henson S, Jackson AB, Richards JS. Obesity intervention in persons with spinal cord injury. Spinal Cord. 2006;44(2):82-91. [PMID:16103891]

http://dx.doi.org/10.1038/sj.sc.3101818

28. Carlson KF, Wilt TJ, Taylor BC, Goldish GD, Niewoehner CB, Shamliyan TA, Kane RL. Effect of exercise on disorders of carbohydrate and lipid metabolism in adults with traumatic spinal cord injury: systematic review of the evidence. J Spinal Cord Med. 2009;32(4):361-78.

[PMID:19777857]

29. Liusuwan RA, Widman LM, Abresch RT, Johnson AJ, McDonald CM. Behavioral intervention, exercise, and nutrition education to improve health and fitness (BENEfit) in adolescents with mobility impairment due to spinal cord dysfunction. J Spinal Cord Med. 2007;30(Suppl 1):S119-26. [PMID:17874697]

30. Grundy SM, Pasternak R, Greenland P, Smith S Jr, Fuster V. Assessment of cardiovascular risk by use of multiplerisk-factor assessment equations: a statement for healthcare professionals from the American Heart Association and the American College of Cardiology. Circulation. 1999; 100(13):1481-92. [PMID:10500053] http://dx.doi.org/10.1161/01.CIR.100.13.1481

31. West JA, Miller NH, Parker KM, Senneca D, Ghandour G, Clark M, Greenwald G, Heller RS, Fowler MB, DeBusk RF. A comprehensive management system for heart failure improves clinical outcomes and reduces medical resource utilization. Am J Cardiol. 1997;79(1):58-63.

[PMID:9024737]

http://dx.doi.org/10.1016/S0002-9149(96)00676-5

32. American Thoracic Society; American College of Chest Physicians. ATS/ACCP Statement on cardiopulmonary exercise testing. Am J Respir Crit Care Med. 2003;167(2): 211-77. [PMID:12524257] http://dx.doi.org/10.1164/rccm.167.2.211

33. Borg GA. Borg's perceived exertion and pain scales. Champaign (IL): Human Kinetics, 1998.

34. Washburn RA, Zhu W, McAuley E, Frogley M, Figoni SF. The physical activity scale for individuals with physical disabilities: development and evaluation. Arch Phys Med 
Rehabil. 2002;83(2):193-200. [PMID:11833022]

http://dx.doi.org/10.1053/apmr.2002.27467

35. Myers J, Kaykha A, George S, Abella J, Zaheer N, Lear S, Yamazaki T, Froelicher V. Fitness versus physical activity patterns in predicting mortality in men. Am J Med. 2004; 117(12):912-18. [PMID:15629729]

http://dx.doi.org/10.1016/j.amjmed.2004.06.047

36. Collins EG, Gater D, Kiratli J, Butler J, Hanson K, Langbein WE. Energy cost of physical activities in persons with spinal cord injury. Med Sci Sports Exerc. 2010;42(4):691-700. [PMID:19952846] http://dx.doi.org/10.1249/MSS.0b013e3181bb902f

37. Crouter SE, Clowers KG, Bassett DR Jr. A novel method for using accelerometer data to predict energy expenditure. J Appl Physiol. 2006;100(4):1324-31. [PMID:16322367] http://dx.doi.org/10.1152/japplphysiol.00818.2005

38. Block G, Woods M, Potosky A, Clifford C. Validation of a self-administered diet history questionnaire using multiple diet records. J Clin Epidemiol. 1990;43(12):1327-35.

[PMID:2254769] http://dx.doi.org/10.1016/0895-4356(90)90099-B

39. Centers for Disease Control and Prevention (CDC). Trends in intake of energy and macronutrients-United States, 1971-2000. MMWR Morb Mortal Wkly Rep. 2004; 53(4):80-82. [PMID:14762332]

40. U.S. Department of Health and Human Services. Healthy People 2020 report. Washington (DC): Department of Health and Human Services; 2012. Available from: http:// www.healthypeople.gov/2020/topicsobjectives2020/pdfs/ HP2020objectives.pdf

41. Haskell WL, Alderman EL, Fair JM, Maron DJ, Mackey SF, Superko HR, Williams PT, Johnstone IM, Champagne MA, Krauss RM, Farquhar JW. Effects of intensive multiple risk factor reduction on coronary atherosclerosis and clinical cardiac events in men and women with coronary artery disease. The Stanford Coronary Risk Intervention Project (SCRIP). Circulation. 1994;89(3):975-90.

[PMID:8124838]

http://dx.doi.org/10.1161/01.CIR.89.3.975

42. Devillard X, Rimaud D, Roche F, Calmels P. Effects of training programs for spinal cord injury. Ann Readapt Med Phys. 2007;50(6):490-98, 480-89. [PMID:17482709] http://dx.doi.org/10.1016/j.annrmp.2007.04.013

43. Pyörälä M, Miettinen H, Laakso M, Pyörälä K. Plasma insulin and all-cause, cardiovascular, and noncardiovascular mortality: the 22-year follow-up results of the Helsinki Policemen Study. Diabetes Care. 2000;23(8):1097-1102. [PMID:10937504] http://dx.doi.org/10.2337/diacare.23.8.1097
44. Bauman WA, Spungen AM. Disorders of carbohydrate and lipid metabolism in veterans with paraplegia or quadriplegia: a model of premature aging. Metabolism. 1994;43(6): 749-56. [PMID:8201966] http://dx.doi.org/10.1016/0026-0495(94)90126-0

45. Bao W, Srinivasan SR, Berenson GS. Persistent elevation of plasma insulin levels is associated with increased cardiovascular risk in children and young adults. The Bogalusa Heart Study. Circulation. 1996;93(1):54-59.

[PMID:8616941] http://dx.doi.org/10.1161/01.CIR.93.1.54

46. Gorgey AS, Gater DR. Prevalence of obesity after spinal cord injury. Top Spinal Cord Inj Rehabil. 2007;12:1-7.

http://dx.doi.org/10.1310/sci1204-1

47. Gater DR Jr. Obesity after spinal cord injury. Phys Med Rehabil Clin N Am. 2007;18(2):333-51, vii. [PMID:17543776] http://dx.doi.org/10.1016/j.pmr.2007.03.004

48. Anson CA, Shepherd C. Incidence of secondary complications in spinal cord injury. Int J Rehabil Res. 1996;19(1): 55-66. [PMID:8730544] http://dx.doi.org/10.1097/00004356-199603000-00006

49. Hicks AL, Martin KA, Ditor DS, Latimer AE, Craven C, Bugaresti J, McCartney N. Long-term exercise training in persons with spinal cord injury: effects on strength, arm ergometry performance and psychological well-being. Spinal Cord. 2003;41(1):34-43. [PMID:12494319] http://dx.doi.org/10.1038/sj.sc.3101389

50. Ginis KA, Hicks AL. Exercise research issues in the spinal cord injured population. Exerc Sport Sci Rev. 2005;33(1): 49-53. [PMID:15640721]

Submitted for publication November 10, 2011. Accepted in revised form March 7, 2012.

This article and any supplementary material should be cited as follows:

Myers J, Gopalan R, Shahoumian T, Kiratli J. Effects of customized risk reduction program on cardiovascular risk in males with spinal cord injury. J Rehabil Res Dev. 2012;49(9):1355-64.

http://dx.doi.org/10.1682/JRRD.2011.11.0215

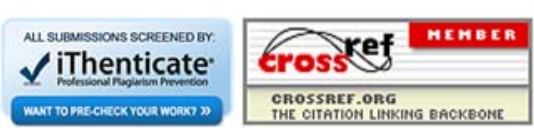

